Article

\title{
Is Factor Investing Sustainable after Price Impact Costs? The Capacity of Factor Investing in Korea
}

\author{
Jungmu Kim ${ }^{1}$ (1) and Yuen Jung Park ${ }^{2, *}$ \\ 1 Department of Business Administration, Yeungnam University, Gyeongsan 38541, Korea \\ 2 Department of Finance, College of Business, Hallym University, Chuncheon 24252, Korea \\ * Correspondence: yjpark@hallym.ac.kr; Tel.: +82-33-248-1855
}

Received: 29 July 2019; Accepted: 28 August 2019; Published: 3 September 2019

check for updates

\begin{abstract}
This study investigates whether the profitability of various factor investments is sustainable after costs due to price impact, and estimates the capacity of strategies in the Korean stock market. With various initial amounts invested as of the end of December 2000, we analyze after-cost-returns on factor investing during the period from January 2000 to December 2017, and estimate the break-even fund size and maximal profit fund size. To this end, whenever rebalancing factor-investment portfolios based on trading rules, the number of shares of stocks to be bought and sold is computed and the price impact costs of the transactions are taken into account. This procedure computes the implicit cost of trading of factor investing to produce after-cost-returns for various initial amount invested. While the momentum and value factors perform well before price impact costs, the profitability factor performs better after price impact costs. More specifically, the break-even fund size is estimated to be 1.4 trillion Korean won (KRW), and the maximal profit generating fund size is estimated to be 750 billion KRW which could attain a monthly net profit of 1.9 billion KRW over the sample period.
\end{abstract}

Keywords: fund capacity; factor investing; pension fund; price impact; sustainable profit

\section{Introduction}

Factor investing is an investment strategy based on market anomalies that have been observed from past data [1-5]. Recently, a growing amount of passive funds are using factor-based investment strategies. According to Morningstar Inc., the amount of money invested in such exchange traded funds (ETFs) was nearly 800 billion dollars as of 2018. In the trend toward this new investment technology, the National Pension Service of Korea (NPS), a public pension fund in South Korea, has decided to introduce factor investing to the management of its pension fund in order to lower commission fees and increase transparency of the fund management.

However, there is criticism that factor investing is not appropriate for the management of pension funds which should pursue stability and sustainability because the effectiveness of factor investing has not yet been verified and is still controversial among practitioners and academics [6-9]. Typically, the effectiveness of factor investing is investigated by a so-called back-test which simulates the investment strategy following its own logic of portfolio selection with historical data. The inevitable flaw of back-tests is the fact that past profits do not guarantee future profits.

There are several reasons why back-tests cannot guarantee sustainable future returns. First, there always exists a possibility of a data-snooping bias, and overfitting by data-snooping often harms future performance [10]. Even, Linnainmaa and Roberts [9] show that most of accounting-based anomalies fail to persist when data over 90 years are tested, and they argue that such anomalies found in literature are likely an artifact of data snooping. This criticism has been defensed somehow by using modern statistical techniques $[7,11]$. Since many studies have already discussed this issue, we do not focus on it. 
Second, once a strategy is publicly known, many investors exploit the same strategy in the market so that the known strategy is overpriced and generates lower return in the future. This risk is called "herding risk." Scharfstein and Stein [12] and Banerjee [13] suggested a model of herd behavior in financial markets. Marquering et al. [14] examined if well-known stock market anomalies persist after publication of academic papers about them, in effect finding strong evidences that the timing of disappearing or weakening anomalies coincides with the timing of publications. Herding risk also exists in factor investing. This issue is well-documented by Krkoska and Schenk-Hoppé [15] and references therein. The herding risk is closely associated with price impacts, which will be explained below.

Finally, market friction costs such as price impact are involved in trading. If liquidity is not enough for trades to be assimilated within bid/ask spreads, trades with significant amounts should buy at higher prices and sell at lower prices than market prices. Thus, a huge size of funds can significantly impact market prices and consequently the profitability might not be the same with the back-test results using recorded data; the actual fund profits would be much smaller than the hypothetical performance. The problem of transaction costs caused by price impacts can create a considerable problem especially for large-scale funds such as pension funds of Korea. According to NPS, as of the end of 2017, the national pension fund was investing 131 trillion won (or 21\% of the fund) in Korean domestic stocks, with the direct and consignment investments reaching 71 trillion KRW and 60 trillion KRW, respectively. If some of such huge amounts of money is invested directly in a factor investment with domestic stocks, or are consigned through ETFs, the actual profit after costs would be very different from the back-test results that have been reported in previous studies.

In this regard, we address the second question of how the price impact costs affect the profitability of factor investing and estimate the capacity of each factor investing strategy in the Korean stock market. Even though many papers have analyzed whether the Korean stock market has anomalies and whether the strategies exploiting well-known anomalies is applicable to the Korean stock market [16-20], studies considering price impacts are scarce. We contribute to the literature by filling this gap. Whether the factor investing is sustainable even after considering transaction costs is still controversial in the international markets. Therefore, our study can provide the literature with additional evidence in an emerging market, Korea. The reason that we analyzed the Korean stock market is clear. The main audiences that we target are fund managers of NPS which is considering factor-investment in the Korean stock market. Even though NPS is a public pension fund of a small domestic market, the fund is the third largest pension fund around the world following public pension funds of Japan and Norway.

The consideration of price impact costs is crucially important for practitioners of Korea including fund managers of NPS as well as asset management firms that have commitment of the pension fund of NPS. As we emphasized earlier, given the fact that the fund size of the NPS is not ignorable and that the NPS is considering factor investing, it is necessary to examine the efficacy of the strategy in consideration of price impacts. That is, fund managers would be very interested in how much transaction costs from price shocks would reduce the profitability of a factor investment. In particular, our estimation of break-even fund size that eliminates all profits from factor investing is helpful because it has implications for how much of the portion of the pension fund can be directly invested or commissioned to invest in the domestic stock market in order to implement factor investing.

We also suggest the maximal profit fund size with which a fund can reach its maximum profit. While after-cost-returns on factor investing decrease with the fund size, the amount of the profit increases when more amounts are invested. Therefore, there exists a maximal profit fund size. With the break-even fund sizes, we also estimate the maximal profit fund sizes for various strategies. This implication can be useful for practical purposes. 


\section{Literature Review}

\subsection{Stock Market Anomalies and Factor Investing}

According to Hou et al. [8], the number of anomalies that have been reported by academic papers is 452 in six categories of momentum, value, investment, profitability, intangibles, and trading frictions. Factor investing is an investment strategy that exploits well-known anomalies. For example, the momentum anomaly, first found by Jegadeesh and Titman [21], is a phenomenon that stocks with higher past return tend to have higher returns in the future. In this case, the factor variable is a past return of each stock and the factor investing portfolio includes, for example, the top 10\% stocks based on past returns. We provide a description of factor variables and factor investing strategies in the methodology section.

With these findings, some papers have investigated if the anomalies found in the U.S. market are applicable to the Korean stock market. For instance, Chui and Wei [16] examine if there exist anomalies such as market beta, value factor, and size factor in five emerging markets including Korea. They find that the value effect and the size effect are significant in the Korean market. They also discover that small firms in Korea have experienced higher returns in January and argue that the results come from the majority of investors in Korea being mainly individuals. Hameed and Kusnadi [17] explore whether momentum factor strategy is profitable in Asian markets including Korea. They show that significant momentum profits are not produced by momentum factor strategies. Cakici et al. [18] investigate the effect of local and global factors effects in 18 emerging stock markets including Korea and conclude that the local factor is more influential for emerging markets. Nartea et al. [19] test whether extreme positive returns (MAX) effect exists in Korea and find the substantially negative MAX effect similar to the US stock market. However, the idiosyncratic volatility effect cannot be reversed by the MAX effect in the Korean stock market. Hung and Banerjee [20] analyze the momentum strategies utilizing a score function in three Asian countries including Korea and find that average scores of the momentum profits in these markets are close to zero. In addition, whereas in the U.S. market the winner stocks get significantly positive scores, in all the three markets the scores of the winner portfolio are statistically insignificant.

Even though these studies have analyzed the profitability of factor investing in the Korean stock market, none has taken the transaction costs into account. With a database of Elkins/McSherry, a firm which collects records on transactions by institutional traders, Domowitz et al. [22] estimated price impact cost by institutional investors in 12 countries including Korea. However, they do not connect the price impact cost to the effect on portfolio profitability. Papers considering the effect of price impact costs on factor investing profits in the Korean stock market are still rare. Our study fills this gap. To our best knowledge, we are the first to apply price impact cost to the profitability of factor investing.

\subsection{Price Impact Costs}

Although there is no single definition of investment capacity, $\mathrm{O}^{\prime}$ Neill and Warren [23] provide an excellent literature review about issues and methods for fund capacity evaluation. According to them, investment capacity has been defined and measured in three ways: threshold capacity, terminal capacity, and wealth-maximizing capacity. First, the threshold capacity is defined as the fund size that no longer achieves a specified goal of the fund. A typical example of the goal is expected returns on the fund in excess of its benchmark such as the Standard and Poor's 500 Stock Index (S\&P500 Index). Second, terminal capacity is a concept related with a break-even point of fund size above which the fund cannot generate profits any longer. It is well-known that fund performance is negatively related with fund size since transaction costs due to price impact significantly increase with fund size. Third, wealth-maximizing capacity is the fund size with which the maximal profit can be achieved. The increase in fund size results in a decrease in return on the fund, but, at the same time, the dollar amount of profit increases with the amount invested. Therefore, there exists an optimal point in terms of size at which the fund profit reaches a maximum. 
To estimate the capacity of factor investing in this study, we adopt the terminal and wealth-maximizing capacity definition, following Korajczyk and Sadka [24]. Once various after-cost returns depending on fund size are estimated, it is straightforward to estimate the break-even fund size at which the after-cost return becomes zero. The threshold capacity definition is not appropriate for our study because particular objectives depend on funds. We cannot define a threshold for each factor-investing strategy. Nevertheless, our estimation is also helpful even for practitioners who seek threshold capacity. We provide the entire profile of the fund profits and returns depending on fund size. Therefore, our estimation allows one to find out threshold capacity based on his own goal.

Estimating the effect is very difficult because the price impact cost is invisible unlike other transaction costs such as commissions and taxes. That is why there is little research on the quantified effect in the Korean stock market, even though both practitioners and academics understand the fact that price impacts significantly reduce the actual fund performance. One exception is Domowitz et al. [22]. With a database of Elkins/McSherry, a firm that collects records on transactions by institutional traders, Domowitz et al. [22] estimated price impact cost by institutional investors in 12 countries including Korea. However, it is limited to institutional investors' transactions.

Many studies are skeptical for the profitability of factor investing because of limits-to-arbitrage such as transaction costs. For example, Chen et al. [25] examined if the size, value, and momentum factors can make sustainable profits after price impact costs in the U.S. market. Specifically, they estimated the terminal capacity (or break-even fund size) of the three factor-investing strategies and concluded that the capacity is too small for a large volume of funds to make profits.

However, there are papers suggesting some evidence that factor investing is profitable even after accounting for the price impact costs. For example, Frazzini et al. [26] conducted similar research with Chen et al. [25], but they covered data from 19 developed countries and size, value, momentum, and short-term reversal. They found that the price impact cost varies over factors. Specifically, the short-term reversal exhibited the smallest capacity. While the capacities are different across anomalies and countries, they conclude that the main anomalies are implementable even after taking price impact cost into account. Novy-Marx and Velikov [27] analyzed a number of anomalies and showed that the size, value, and profitability factors have the greatest capacity. They argue that transaction costs reduce the expected returns but, when using sophisticated cost-mitigation techniques, the abnormal returns are still significant after accounting for the costs. Li et al. [28] emphasized that the market impact costs may erode the expected returns on factor-investing strategies and showed that the costs are related with some liquidity characteristics like turnover rate and turnover concentration. Based on these findings, they argued that the market impact costs can be reduced when the index construction methods are thoughtfully designed; they suggested sophisticated techniques of factor index design—such as distributing rebalances over multiple periods to mitigate turnover concentration, constraining portfolio selection rules to limit turnover, and weighting by a metric correlated with market impacts.

Some papers have directly estimated the capacity using a functional model of trading costs. Using a trading cost model, Ratcliffe et al. [29] estimated the capacity of smart beta strategies which combine several factors such as momentum, quality, value, size, and defensive factors. Blitz and Marchesini [30] estimated the capacity of investment using factor indexes and showed that the popular factor indexes are severely constrained in limited capacity. Korajczyk and Sadka [24] estimated the entire relation between initial investment and after-cost profits. Thereby, they provide the break-even fund size and wealth-maximizing fund size for the momentum factor strategy. Our approach is closely related to this study. We apply their method to the Korean stock market and analyze a number of anomalies that have been reported. 


\section{Methodology}

\subsection{Transaction Costs Due to the Price Impact}

To estimate price impact costs, we closely follow the method suggested by Korajczyk and Sadka (henceforth, KS) [24]. Unless transaction costs due to price impact are taken into account, the cost of trading individual assets in the portfolio will be given in $x=p q$. However, in actual transactions, especially if large quantities such as pension funds are traded, all supplies are not digested in the top purchase price list, and price shocks are added to the additional transaction costs. If the price impact function is $f(p, q)$, the total cost of organizing the portfolio will be given as follows [31]:

$$
x=p q+\int_{0}^{q} f(p, q) d q
$$

where $p$ is the current price and $q$ is the transaction volume. This study analyzes the price impact function $f(p, q)$ by assuming the model of Breen et al. (henceforth BHK) [32] that has been much addressed in the existing literature [24,33-37]. This is a model in which transaction costs respond flexibly to the size of funds, and profitability deteriorates as the volume of transactions increases. Using these characteristics, we can estimate the break-even fund size with a return rate of zero for various factor investment strategies. The model and estimation methods of each impact function are described in the following sections.

If the fund management approach is a closed-end, the amount of investment will be reduced due to the transaction costs that arise when the portfolio is reorganized on a fixed basis to implement the factor investment strategy. If the value of the portfolio is $x_{t}$ immediately before rebalancing at $t$, and $\bar{x}_{t}$ immediately after reconstruction at $t$, then the transaction cost expenditure is responsible for the relationship of $\bar{x}_{t} \leq x_{t}$. Assuming that the rate of return recorded in our dataset is $R_{t}=\frac{x_{t+1}}{\bar{x}_{t}}-1$, this study estimates the rate of return $r_{t}=\frac{x_{t+1}}{x_{t}}-1$, which takes account of transaction costs due to price shock. If the price impact function is defined based on the BHK model as in Equation (1), it is given $f(p, q)=p\left(e^{\bar{\lambda}^{B H K}} q-1\right)$. According to KS, under these assumptions, the portfolio values immediately before and after rebalancing have the following relationship:

$$
x_{t}=\bar{x}_{t}+\sum_{i \in H}\left[\frac{1}{b_{i, t}}\left(e^{b_{i, t}\left(\omega_{i, t} \bar{x}_{t}-a_{i, t}\right)}-1\right)-\left(\omega_{i, t} \bar{x}_{t}-a_{i, t}\right)\right]+\sum_{i \in N}\left[\frac{1}{b_{i, t}}\left(e^{-b_{i, t} a_{i, t}}-1\right)+a_{i, t}\right],
$$

where $a_{i, t} \equiv \omega_{i, t} \bar{x}_{t-1}\left(1+R_{i, t}\right), b_{i, t} \equiv \frac{\lambda_{i, \tau}^{B H K}}{M V E_{i, \tau}}, \omega_{i, t}$ is a weight of stock $i$ in the portfolio at any time $\mathrm{t}$ in month $\tau$. $\lambda_{i, \tau}^{\mathrm{BHK}}$ is the BHK model price impact coefficient in month $\tau$, and $M V E_{i, \tau}$ is the market value of month $\tau$ for stock $i$. $H$ is a set of stocks that have been included in the portfolio and need weighting adjustment (additional buy or sell) at time $t$. $N$ is a set of stocks that will be totally excluded in the portfolio at time $t$. Refer to the Appendix of KS [24] for the details of the derivation of Equation (2) with the cost function (1).

As discussed earlier, with the observational rate given in the database, we repeatedly estimate the amount of the investment before and after the portfolio adjustment in Equation (2) to estimate the rate of return $r_{t}$ after deducting transaction costs. The detailed estimation algorithms are as follows.

First, assume an initial investment $x_{0}$ and estimate $\bar{x}_{0}$ less the costs incurred in the initial $(t=0)$ portfolio configuration. As shown in Equation (2) the costs of portfolio adjustment are affected by $\bar{x}_{0}$, so the nonlinear equation must be solved. Therefore, estimate the value $\bar{x}_{0}$ of the non-linear equation that satisfies the Equation (2). Until the next portfolio adjustment period $(t=1)$, the retained return on the portfolio is calculated as $x_{1}$ using the rate of return $R_{0}$ recorded in the data. That is, $x_{1}=\bar{x}_{0}\left(1+R_{0}\right)$. If $x_{1}$ is thus calculated, estimate again the value $\bar{x}_{1}$ that satisfies the non-linear Equation (2). In this way, a time series of values can be estimated before and after the cost of the portfolio is deducted until 
the end of the sample period. After deducting costs, the geometric mean return can be calculated as $M G R=\left(\frac{x_{T}}{x_{0}}\right)^{\frac{1}{N}}-1$ where $\mathrm{N}$ is the total number of months in the sample period.

\subsection{Estimation of BHK Price Impact Factors}

KS define the price impact coefficient $\left(\bar{\lambda}^{B H K}\right)$ as the rate of price change relative to the volume of the transaction as shown in the following formula.

$$
\frac{\Delta p}{p}=\bar{\lambda}^{B H K} \Delta q
$$

On the other hand, BHK measures the price impact coefficient $\left(\lambda^{B H K}\right)$ relative to the turnover rate (TURN).

$$
\frac{\Delta p}{p}=\lambda^{B H K} \times T U R N
$$

where TURN is the turnover ratio which is the transaction amount $(\Delta q)$ divided by the number of shares issued $(\mathrm{N})$. Thus, the price impact coefficient of the two models can be found to have a relationship of $\lambda^{B H K}=\bar{\lambda}^{B H K} \times N$.

The U.S. market studies do not estimate price impact coefficients for the entire period. BHK and KS used the following out-of-sample estimation methods to overcome the limitations that minute-per-minute Trade and Quote (TAQ) data were given for only a fraction of the period. First, BHK and KS estimated the price impact coefficient using the transaction data of $5 \mathrm{~min}$ to $30 \mathrm{~min}$ over some period (time-series regression), and then estimate the cross section of the price impact coefficient using the firm's characteristic variables over time (Fama-MacBeth type regression). The price impact coefficients estimated through this process are applied to out-of-sample period by substituting observations of the firm's characteristic variables during out-of-sample period. The results of KS are given in the following Equation (5).

In this study, the coefficients estimated in the U.S. market by KS are used because intraday transaction data is not available to public in Korea. It is assumed that the cross-sectional relationship between the price impact coefficient and the firm's characteristic variables applies structurally to the domestic market. The cross-sectional relationship estimated by KS is as follows:

$$
\begin{gathered}
\bar{\lambda}^{B H K}=2.48+0.25 X_{1}-0.61 X_{2}-0.63 X_{3}+0.34 X_{4}-1.68 X_{5}+4.15 X_{6} \\
-3.42 X_{7}-0.26 X_{8}+3.23 X_{9}
\end{gathered}
$$

where $X_{1}$ is the market capitalization of the stock immediately before the end of the month divided by the total market value of the Korea Composite Stock Price Index (KOSPI) less $1, X_{2}$ is the trading volumes from the last three months divided by the average trading volumes of KOSPI shares less 1 , $X_{3}$ is the price of the stock at the end of the month divided by the price 6 months ago less $1, X_{4}$ is the absolute value of $X_{3}$. $X_{5}$ is a dummy variable with a value of 1 when included in the KOSPI200 index or $0 . X_{6}$ represents dividend yield, and $X_{7}$ is the coefficient of determination, $\mathrm{R}^{2}$, from regression of the firm's monthly percentage stock price change on the monthly percentage change in the S\&P500 Index, estimated over the previous 36 months. $X_{8}$ indicates the dummy variable with a value of 1 for the shares traded in KOPSI and $X_{9}$ is the reciprocal of the last month's closing. The coefficient in Equation (5) is the estimate of KS.

It is necessary to clarify that this study examines how the profitability of the factor investment in the Korean market is affected by the initial investment under the assumption that the cross-sectional structure of the price impact function estimated by KS is equally established in the Korean market. Nevertheless, we believe that such an assumption does not significantly affect the implication on price impact costs because most of the determinants of cross-sectional relationships $\left(X_{1} \sim X_{9}\right)$ are measured by ratio variables (relative measures), not absolute values. It is unlikely that they will become 
unrealistically different from the Korean market. What we suggest is a bench-mark case to overcome the limitation of data. Starting from the benchmark case we suggest, one can adjust the constant term in Equation (5) to reflect the structural difference between the U.S. and Korean markets. If the intercept estimate is adjusted, it will affect the price impact cost equally for all stocks and make a parallel shift to the cost. Therefore, it is straightforward to consider the effect. We leave a direct estimation of a cost function using intraday transaction data as a future work until the data is available.

\subsection{Factor Investment Strategy}

In this study, a factor investment strategy is carried out by using factors such as momentum, value, profitability, market friction, lottery tendency, and low volatility, which are reported as unusual phenomena in existing literature and are widely utilized in practice. The effects of a factor investment strategy on profitability are then reviewed, taking into account the effects of transaction costs due to price impact. The definitions and estimation methods of each factor are detailed separately in the following sections. In this section, we describe an investment strategy that is commonly applied when a single factor is defined.

In academic papers $[21,38,39]$, long-short strategies have been examined. However, in practice, long-only portfolios are managed because short-sale is prohibited by law or short-sale is costly [40-42]. Although the Korean stock market regulation permits institutional investors to take short on stocks, short-sales are not very common for mutual funds because short-sales are costly as well as risky. In order to focus on the assessment of feasibility of factor investing, we try to reflect the practical issue and examine long-only strategies except long-short strategies. Although the consideration of short leg can give more implications to practitioners, we leave such an extension for future research.

$\mathrm{L} / \mathrm{M} / \mathrm{N}$ strategy means a long-only strategy in which a factor is estimated from data over an $\mathrm{L}$ month, wait for an $\mathrm{M}$ month, and have an item that meets the criteria of the factor for an $\mathrm{N}$ month. In this study, we wait one month after estimating the factor to control issues such as microstructure and short-term rebound in the market. That is, set to $\mathrm{M}=1$. N is to 3 or 6 . In other words, a portfolio adjustment is made after holding the item for three or six months. Thus, portfolio adjustments are made every three or six months. The estimated period $\mathrm{L}$ of the factor is from 1 to 12 , which is defined by various factors.

Taking momentum factor investment as an example, the following is the description of the transaction strategy based on previous returns (PRET). For the PRET $(10,0) / 1 / 3$ strategy, the stock is classified and held for three months after waiting for one month, using the cumulative rate of return (PRET $(10,0)$ ). More specifically, the purchase portfolio is formed by arranging the KOSPI listed shares in the 10th quarter based on the cumulative yield PRET $(10,0)$ from January to November 2000. After waiting for one month, we shall purchase the product by setting the weight based on the market capitalization at the end of December $2000(t=0)$. By the end of March 2001, we will hold it and readjust our portfolio $(t=1)$. To continue the investment, the portfolio will be formed with $\operatorname{PRET}(10,0)$ as of the end of February 2001 and reflected in the adjustment of the portfolio in March 2001. Portfolio adjustments result in the purchase or sale of only as needed stocks by comparing the composition and weight of the portfolio of $\mathrm{t}-1$ to those of the target portfolio of $t$, in order to minimize price impact.

Now, we introduce the stock market anomalies that have been found in literature and define factor variables which will be used in our empirical analysis. Harvey et al. [7] and Hou et al. [8] provide a great review on anomalies that have been reported in academic papers. All the factor variables that will be used in the empirical part are defined as below:

- Momentum Factor

Estimates of momentum return (PRET(10,0), PRET $(10,5))$ follow the research methods of Jegadeesh and Titman [21]. The rate of return from the previous 11 months to the current month and from the past 11 months to 6 months is accumulated and calculated, respectively. We take a long position on 
the highest-decile portfolio (the highest past return stocks) because of the high return on the previous winner portfolio in the past.

- Value Factor

The ratio of book value to market value $(\mathrm{B} / \mathrm{M})$ is calculated by dividing capital totals minus preferred stock capital of the year by the market capitalization at the end of December $t-1$. The earnings-to-price ratio $(\mathrm{E} / \mathrm{P})$ is calculated by dividing the current profit at the end of year $t-1$ by the total market value at the end of December $t-2$ by the method of Basu [43]. We take a long position on the highest-decile portfolio (the most undervalued stocks) because of high return on undervalued stocks.

- Profitability Factor

The gross profit on assets (GPA) is calculated by dividing the gross profit margin at the end of $t-1$ by the total assets at the end of $t-1$ by the method of Novy-Marx [44]. We take a long position on the highest-decile portfolio because of the high return of stocks with a high profitability index.

- Market friction factor

The illiquidity (ILLIQ) is calculated by dividing absolute value of the daily rate of return by the transaction amount using Amihud [45]. We take a long position on the highest-decile portfolio (the most illiquid stocks).

- Lottery-like Factor

The daily maximum rate of return $(\operatorname{MAX}(1))$ uses the daily maximum rate of return for $t$ months in accordance with the study by Bali et al. [46]. Skewness (SKEW(1)) uses the third moment of daily return in a month in accordance with Bali et al. [46]. We buy stocks with a weak tendency to lottery. In other words, we take a long position on the highest-decile portfolio.

- Defensive Factor

The idiosyncratic volatility (IVOL(12)) is calculated by the method in Ang et al. [47]. It is estimated as the standard deviation of residuals for the Fama and French three-factor model $\left(R_{t}=a+b M K T_{t}+s S M B_{t}+h H M L_{t}+\varepsilon_{t}\right.$, for excess return $\mathrm{R}$, market factor MKT, size factor SMB, and value factor HML) with the daily returns over 12 months as of the last trading day of each month, respectively. Market beta $\left(\beta_{M K T}(12)\right)$ represents a beta for market portfolio returns. We take a long position on the lowest-decile portfolio (the most defensive stocks).

\section{Empirical Results}

\subsection{Data}

The share price data and corporate accounting data used in this study are provided by FnGuide and are collected through DataGuide. Factor investments are analyzed for shares listed on the KOSPI market from early January 2001 to the end of December 2017 but in some cases, data from 2000 are also included to estimate factor variables. This includes even the delisted companies and assumes a return on the delisted month is $-100 \%$. The monthly rate of returns is calculated by accumulating the monthly disclosure rate of returns, which can be obtained via the DataGuide.

The reason that we make this assumption is to be conservative in consideration of market microstructure. Typically, when a company is close to default, a trading halt of its stock occurs and investors cannot trade on exchange for one or two weeks. If the rebalance date is during this period, the halted stock should be excluded in a portfolio. Even if there is some delisting return after the halt period, price impact for massive trading is significant because of low liquidity. Thus, it is reasonable that we make such a conservative assumption of a $100 \%$ loss at delisting. 


\subsection{Price Impact Coefficient}

Table 1 is the result of calculating the price impact factor in the manner described earlier. The left panel shows the summary statistics of the price impact coefficient $\left(\bar{\lambda}^{\mathrm{BHK}}\right)$ relative to the volume of the transaction, and the right panel shows the summary statistics of the price impact coefficient $\left(\lambda^{\mathrm{BHK}}\right)$ relative to the turnover. At the bottom of the table, panels A to F show the results of each displayed portfolio of buying factor investment strategy.

$\bar{\lambda}^{\mathrm{BHK}}$ is the cost (bp) of a 1000-share transaction and $\lambda^{\mathrm{BHK}}$ is the cost (\%) of a $0.1 \%$ transaction of shares outstanding. For example, a portfolio of momentum strategies using 11-month historical rate of returns has an average price impact coefficient $\left(\bar{\lambda}^{\mathrm{BHK}}\right)$ of 1.9 relative to the volume of the transaction. This implies a cost of $1.9 \mathrm{bp}$ for 1000-share transactions. Looking at the price impact coefficient $\left(\lambda^{\mathrm{BHK}}\right)$ relative to the turnover ratio of the right-hand panel shows that it is $6.72 \%$ on average, which means that a $0.1 \%$ transaction of the issued shares will incur a cost of $6.72 \%$.

Table 1. Price impact coefficients. This table shows the price impact coefficients of long legs for various factor investing strategies. $\bar{\lambda}^{\mathrm{BHK}}$ represents the trading cost (basis points) when 1000 shares are traded. We winsorize the coefficient at 5 and 95\% values in the Korea Composite Stock Price Index (KOSPI) universe. $\lambda^{\mathrm{BHK}}$ is $\bar{\lambda}^{\mathrm{BHK}}$ times the number of shares outstanding, representing the trading cost (\%) when $0.1 \%$ of shares outstanding are traded.

\begin{tabular}{|c|c|c|c|c|c|c|c|c|}
\hline & \multicolumn{4}{|c|}{$\bar{\lambda}$ внК } & \multicolumn{4}{|c|}{$\lambda^{\mathrm{BHK}}$} \\
\hline & Mean & STD & Min & $\operatorname{Max}$ & Mean & STD & Min & $\operatorname{Max}$ \\
\hline \multicolumn{9}{|c|}{ Panel A: Momentum } \\
\hline $\operatorname{PRET}(10,0) / 1 / 3$ & 1.90 & 0.44 & 1.49 & 2.72 & 6.72 & 14.14 & 0.04 & 210.83 \\
\hline $\operatorname{PRET}(10,0) / 1 / 6$ & 1.90 & 0.43 & 1.49 & 2.72 & 6.46 & 12.94 & 0.04 & 197.91 \\
\hline $\operatorname{PRET}(10,5) / 1 / 3$ & 2.01 & 0.48 & 1.49 & 2.72 & 7.07 & 14.70 & 0.04 & 310.83 \\
\hline $\operatorname{PRET}(10,5) / 1 / 6$ & 2.00 & 0.47 & 1.49 & 2.72 & 6.89 & 14.07 & 0.04 & 307.07 \\
\hline \multicolumn{9}{|c|}{ Panel B: Value } \\
\hline $\mathrm{BM} / 1 / 3$ & 2.16 & 0.42 & 1.49 & 2.72 & 5.35 & 15.61 & 0.07 & 174.52 \\
\hline $\mathrm{BM} / 1 / 6$ & 2.16 & 0.42 & 1.49 & 2.72 & 5.31 & 15.62 & 0.07 & 174.52 \\
\hline $\mathrm{EP} / 1 / 3$ & 2.14 & 0.45 & 1.49 & 2.72 & 6.84 & 18.41 & 0.08 & 197.91 \\
\hline $\mathrm{EP} / 1 / 6$ & 2.14 & 0.45 & 1.49 & 2.72 & 6.82 & 18.44 & 0.08 & 197.91 \\
\hline \multicolumn{9}{|c|}{ Panel C: Profitability } \\
\hline GPA/1/3 & 2.07 & 0.49 & 1.49 & 2.72 & 6.56 & 11.37 & 0.00 & 84.87 \\
\hline GPA/1/6 & 2.07 & 0.49 & 1.49 & 2.72 & 6.54 & 11.40 & 0.00 & 84.87 \\
\hline \multicolumn{9}{|l|}{ Panel D: Friction } \\
\hline ILLIQ $1 / 1 / 3$ & 2.50 & 0.22 & 1.49 & 2.72 & 2.09 & 3.80 & 0.03 & 70.97 \\
\hline ILLIQ 1/1/6 & 2.50 & 0.23 & 1.49 & 2.72 & 2.08 & 3.71 & 0.03 & 70.97 \\
\hline \multicolumn{9}{|c|}{ Panel E: Lottery-Like } \\
\hline $\operatorname{MAX} 1 / 1 / 3$ & 2.27 & 0.45 & 1.49 & 2.72 & 7.68 & 19.00 & 0.00 & 228.11 \\
\hline MAX 1/1/6 & 2.27 & 0.45 & 1.49 & 2.72 & 7.52 & 18.50 & 0.00 & 228.11 \\
\hline SKEW 1/1/3 & 2.11 & 0.48 & 1.49 & 2.72 & 6.76 & 14.54 & 0.06 & 219.12 \\
\hline SKEW 1/1/6 & 2.11 & 0.47 & 1.49 & 2.72 & 6.96 & 15.56 & 0.07 & 219.12 \\
\hline \multicolumn{9}{|c|}{ Panel F: Defensive } \\
\hline IVOL $12 / 1 / 3$ & 2.22 & 0.47 & 1.49 & 2.72 & 12.18 & 27.89 & 0.11 & 219.12 \\
\hline IVOL 12/1/6 & 2.22 & 0.47 & 1.49 & 2.72 & 12.18 & 27.96 & 0.11 & 219.12 \\
\hline$\beta_{\text {MKT }} 12 / 1 / 3$ & 2.41 & 0.39 & 1.49 & 2.72 & 4.65 & 11.27 & 0.04 & 228.11 \\
\hline$\beta_{\mathrm{MKT}} 12 / 1 / 6$ & 2.41 & 0.39 & 1.49 & 2.72 & 4.62 & 11.99 & 0.04 & 228.11 \\
\hline
\end{tabular}

Note: The definition of each factor variable is given in Section 2. 
From the perspective of the price impact coefficient $\bar{\lambda}^{\mathrm{BHK}}$, it is shown that the trading strategy using the ILLIQ variable is, on average, costly compared to other strategies. This is because the trading strategy is to buy stocks with low turnover and low liquidity.

The effect of price impact coefficients on the return after cost reduction is analyzed in conjunction with the estimated results of the break-even fund size and the maximum profit-generating fund size.

\subsection{Estimation of Terminal Capacity: Break-Even Approach}

In this section, we look at the profitability of our factor investments for a number of initial investments. To help in understanding, we will explain it through a momentum factor investment, and then analyze the results of various factor investments.

We looked at the momentum investment performance from January 2001 to December 2017 by changing the initial investment amount from zero to 5 billion won as of the end of December 2000. Momentum factor variables are measured by the cumulative return on the previous 11 months, $\operatorname{PRET}(10,0)$, or PRET $(10,5)$, which is the cumulative return on the previous mid-term six-month period.

Figure 1 shows the results using a PRET $(10,5)$ factor. Panel A and B are the result of a portfolio reconstruction with a cycle of 3 months $(\mathrm{N}=3)$ or 6 months $(\mathrm{N}=6)$, respectively. Blue solid line is the result of a value-weighted portfolio, and red dotted line is the result of the same weighted portfolio.

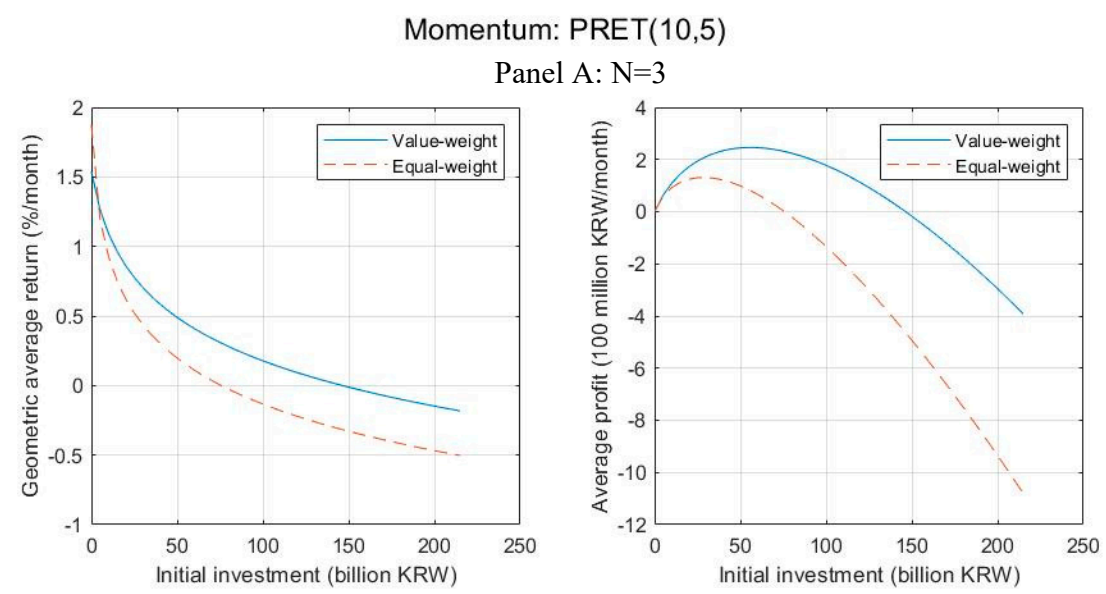

Panel B: $\mathrm{N}=6$
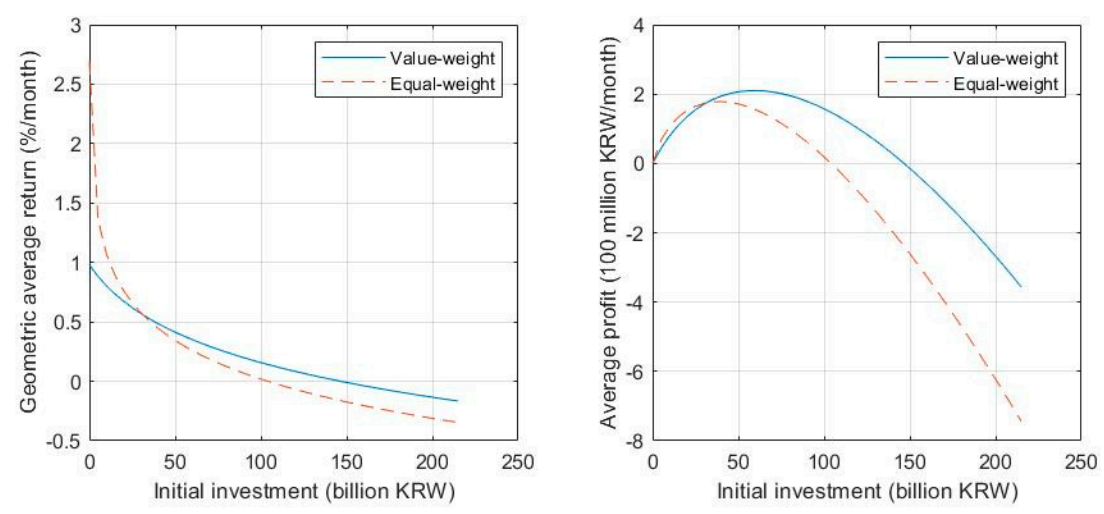

Figure 1. Net-of-cost return on momentum factor.

The graph on the left shows a geometric monthly average rate of returns on the initial investment as of the end of December 2000. As shown in this graph, the average rate of returns on investment is decreasing as the amount of initial investment increases due to serious price impact. Based on a value-weighted portfolio, the rate of returns is $1.54 \%$ per month at a very low level of the initial investment, which corresponds to the results of back testing that has normally been undertaken in the 
literature without a consideration of price impact (the exact figures can be found in Table 2). An initial investment of less than 100 million won can obtain a monthly rate of returns of $1.5 \%$, but as the amount of investment grows, the rate of returns is decreasing exponentially. The average rate of returns is zero when the initial investment is around 150 billion won (see Table 2 for exact figures). In other words, the break-even operating funds of the momentum factor investment fund is about 150 billion won.

The results of equal-weighted portfolio show more interesting facts. We can obtain the average rate of returns of $1.87 \%$ which is higher than the rate of returns from value-weighted portfolio when the transaction costs due to price shocks are not taken into account. However, the price impact is stronger in the equal-weighted portfolio, resulting in a steep decline in the rate of returns after the transaction costs are deducted. Thus, the break-even operating funds with an average return of zero are determined at about 80 billion won.

Table 2. Break-even initial investment. This table presents the break-even amount (100 million KRW) for various factor investments. Return w/o impact (\%) represents the monthly geometric average return without price impact; i.e., after-cost-return at nearly zero investment. $x_{0}^{B E}$ represents the break-even initial amount invested at the end of 2016 that drives the average net return after cost to zero\%. The sample period is January 2001 to December 2017.

\begin{tabular}{|c|c|c|c|c|}
\hline & \multicolumn{2}{|c|}{ lue-Weighted } & \multicolumn{2}{|c|}{ Equal-Weighted } \\
\hline & Return w/o Impact & $x_{0}^{B E}$ & Return w/o Impact & $x_{0}^{B E}$ \\
\hline \multicolumn{5}{|c|}{ Panel A: Momentum } \\
\hline $\operatorname{PRET}(10,0) / 1 / 3$ & 1.56 & 3213 & 1.94 & 1346 \\
\hline $\operatorname{PRET}(10,0) / 1 / 6$ & 1.40 & 3371 & 2.96 & 2279 \\
\hline $\operatorname{PRET}(10,5) / 1 / 3$ & 1.54 & 1463 & 1.87 & 757 \\
\hline $\operatorname{PRET}(10,5) / 1 / 6$ & 0.98 & 1466 & 2.69 & 1040 \\
\hline \multicolumn{5}{|l|}{ Panel B: Value } \\
\hline $\mathrm{BM} / 1 / 3$ & 1.50 & 1863 & 2.26 & 4154 \\
\hline $\mathrm{BM} / 1 / 6$ & 1.57 & 2273 & 2.86 & 5538 \\
\hline $\mathrm{EP} / 1 / 3$ & 1.21 & 1575 & 1.21 & 1522 \\
\hline $\mathrm{EP} / 1 / 6$ & 1.26 & 2033 & 1.66 & 2186 \\
\hline \multicolumn{5}{|c|}{ Panel C: Profitability } \\
\hline GPA/1/3 & 0.55 & 14,479 & 1.31 & 5228 \\
\hline GPA/1/6 & 0.61 & 17,589 & 1.41 & 6731 \\
\hline \multicolumn{5}{|l|}{ Panel D: Friction } \\
\hline ILLIQ 1/1/3 & 0.84 & 807 & 1.94 & 1574 \\
\hline ILLIQ 1/1/6 & 0.91 & 1416 & 1.95 & 2727 \\
\hline \multicolumn{5}{|c|}{ Panel E: Lottery-Like } \\
\hline $\operatorname{MAX} 1 / 1 / 3$ & 1.06 & 374 & 1.02 & 150 \\
\hline $\operatorname{MAX} 1 / 1 / 6$ & 0.29 & 262 & 1.10 & 1058 \\
\hline SKEW 1/1/3 & 0.77 & 266 & 1.17 & 330 \\
\hline SKEW 1/1/6 & 0.91 & 835 & 1.20 & 864 \\
\hline \multicolumn{5}{|c|}{ Panel F: Defensive } \\
\hline IVOL $12 / 1 / 3$ & 0.82 & 4771 & 1.48 & 3055 \\
\hline IVOL 12/1/6 & 0.84 & 11,654 & 1.59 & 4017 \\
\hline$\beta_{\mathrm{MKT}} 12 / 1 / 3$ & 0.68 & 389 & 0.93 & 182 \\
\hline$\beta_{\mathrm{MKT}} 12 / 1 / 6$ & 0.37 & 335 & 0.90 & 1077 \\
\hline
\end{tabular}

Note: The definition of each factor variable is given in Section 2. To convert the currency value, one can apply an exchange rate of $1200 \mathrm{KRW} / \mathrm{USD}$, a value as of August 2019 or simply apply $1000 \mathrm{KRW} / \mathrm{USD}$ which is close to the historical average of the KRW/USD exchange rate. 
The graph on the left side of panel B is the result when assuming a six-month holding period. The longer the holding period is, the higher the break-even point is due to the lower price impact, but the average profitability of the six-month reconstruction strategy is different from the average profitability of the three-month reconstruction strategy, making it difficult to compare it simply. This is because updating factor information may help increase profitability. For the momentum factor investment, the break-even point with value weighting scheme is around 150 billion won, and the break-even point with equal weighting scheme is determined at 100 billion won level, whose break-even point is higher than the point of three-month reconstruction strategy. However, this is not necessarily the effect of price-impact mitigation by rebalancing at a lower frequency.

\subsection{Estimation of Wealth-Maximizing Capacity}

Another interesting analysis that can be done from empirical analysis is to estimate the maximum profit operating funds. The larger the initial investment funds, the higher the price impact, the lower the return on the initial investment, but because of the high initial investment funds, the rate of returns on the factor investment may be higher. Therefore, the right side of the graph on Figure 1 shows absolute amount of profits (monthly average return $\times$ initial investment) for various initial investments. As shown in the upper-right panel of Figure 1, at an appropriate level (around 30 billion won), the increase in equal-weighted rate of returns by increasing the initial investment is greater than the decrease in equal-weighted rate of returns by enlarging the price impact, so the absolute amount of profits increases. However, for initial investments larger than about 30 billion won, absolute amount of profits can be declining because of the greater effect of reducing rate of returns. Therefore, the initial investment that can generate the maximum profit is 30 billion won. In other words, if a factor investment fund is operated on a scale of 55 billion won from the end of December 2000, it would mean that a monthly average maximum profit can be 2.5 billion. If the amount of initial investment is larger than or smaller than 55 billion won, the average amount of profits will decrease. For the equal-weighted strategy, operating 30 billion won was able to generate 1.3 billion won in maximum profits. Detailed figures are available in Table 3.

Table 3. Maximum profit initial investment. This table shows the initial investment amount $\left(x_{0}^{\operatorname{Max}}\right.$, 100 million won) that results in the maximum profit. The Max Profit denotes the maximum of monthly average profit (100 million won) which can be reached by an initial investment of $x_{0}^{M a x}$. The sample period is January 2001 to December 2017.

\begin{tabular}{ccccc}
\hline & \multicolumn{2}{c}{ Value-Weighted } & \multicolumn{2}{c}{ Equal-Weighted } \\
\cline { 2 - 5 } & $x_{0}^{\text {Max }}$ & Max Profit & $x_{0}^{\text {Max }}$ & Max Profit \\
\hline \multicolumn{5}{c}{ Panel A: Momentum } \\
\hline PRET(10,0)/1/3 & 1250 & 5.41 & 500 & 2.35 \\
PRET(10,0)/1/6 & 1300 & 5.54 & 850 & 3.87 \\
PRET(10,5)/1/3 & 550 & 2.46 & 300 & 1.31 \\
PRET(10,5)/1/6 & 600 & 2.10 & 400 & 1.78 \\
\hline Panel B: Value & \multicolumn{5}{c}{} \\
\hline BM/1/3 & 700 & 3.09 & 1550 & 7.47 \\
BM/1/6 & 850 & 3.81 & 2050 & 9.97 \\
EP/1/3 & 600 & 2.47 & 600 & 2.45 \\
EP/1/6 & 800 & 3.23 & 850 & 3.61 \\
\hline GPA/1/3 & 6300 & 14.67 & 2000 & 8.88 \\
GPA/1/6 & 7550 & 19.05 & 2550 & 11.67 \\
\hline Panel D: Friction & \multicolumn{5}{c}{ Panel C: Profitability } \\
\hline ILLIQ(1)/1/3 & 350 & 1.08 & \\
ILLIQ(1)/1/6 & 600 & 1.98 & 1000 & 4.82 \\
\hline
\end{tabular}


Table 3. Cont.

\begin{tabular}{|c|c|c|c|c|}
\hline & \multicolumn{2}{|c|}{ Value-Weighted } & \multicolumn{2}{|c|}{ Equal-Weighted } \\
\hline & $x_{0}^{M a x}$ & Max Profit & $x_{0}^{\operatorname{Max}}$ & Max Profit \\
\hline \multicolumn{5}{|c|}{ Panel E: Lottery-Like } \\
\hline $\operatorname{MAX}(1) / 1 / 3$ & 150 & 0.53 & 50 & 0.24 \\
\hline $\operatorname{MAX}(1) / 1 / 6$ & 100 & 0.16 & 400 & 1.62 \\
\hline SKEW $(1) / 1 / 3$ & 100 & 0.33 & 150 & 0.52 \\
\hline SKEW(1)/1/6 & 350 & 1.16 & 350 & 1.36 \\
\hline \multicolumn{5}{|c|}{ Panel F: Defensive } \\
\hline IVOL(12)/1/3 & 2000 & 6.20 & 1150 & 5.16 \\
\hline $\operatorname{IVOL}(12) / 1 / 6$ & 4850 & 15.46 & 1500 & 6.90 \\
\hline$\beta_{\mathrm{MKT}}(12) / 1 / 3$ & 150 & 0.45 & 50 & 0.26 \\
\hline$\beta_{\mathrm{MKT}}(12) / 1 / 6$ & 150 & 0.26 & 450 & 1.50 \\
\hline
\end{tabular}

Note: The definition of each factor variable is given in Section 2. To convert the currency value, one can apply an exchange rate of $1200 \mathrm{KRW/USD}$, a value as of August 2019 or simply apply $1000 \mathrm{KRW} / \mathrm{USD}$ which is close to the historical average of the KRW/USD exchange rate.

\subsection{Other Factor Investment Strategies}

So far, we have estimated the break-even operating funds and the maximum profit-generating operating funds, focusing on the medium-term return PRET $(10,5)$, one of the momentum factors. The same analysis is applied to various factor investments and results are derived and analyzed. Largely, we address six types of factors including 10 factor variables. In addition, a total of 20 strategies were tested by experimenting strategies with a three-month holding period and a six-month holding period.

Table 2 shows the average return on transaction costs before deducting trading costs and the break-even operating funds $\left(x_{0}^{B E}\right)$ for 20 investment strategies. Table 3 shows the maximum profitgenerating initial investment $\left(x_{0}^{\text {Max }}, 100\right.$ million won) and the maximum monthly profit (Max Profit, 100 million won). The results are analyzed according to the type of factor.

Momentum factor investments using cumulative returns for the past 11 months as a factor have a higher average return than those using cumulative returns for the past mid-term six-month period. For value-weighted strategies, the break-even operating funds are more than double when using the past 11 months of momentum factor strategy. In other words, we can see that the price impact of the simple momentum strategy is less than the impact of the past medium-term momentum strategy. The initial investment for maximizing profits is 125 billion won when using a value-weighted PRET $(10,0) / 1 / 3$ strategy, with the maximum monthly average profits being around 5.4 billion won. The same weighted strategy is significantly lower in scale, with an initial operating scale of 50 billion won resulting in a maximum monthly profit of 2.35 billion won.

The value factor investment uses a ratio of book value to market value (BM) or a ratio of earnings per share (EP). The yield before the cost reduction was valued at a level similar to the momentum investment, but the capacity of the funds was evaluated as somewhat low. For example, BM/1/3 value-weighted strategies show that the break-even operating funds is 180 billion won, which is lower than the 300 billion won for the last 11 months of the momentum strategy. EP/1/3 strategy is also worth 160 billion won. Since the value-factor strategy is to buy undervalued shares, it is expected to be stocks with low liquidity due to low market capitalization or low price per share. As a result, the price impact appears to be relatively large. As shown in Table 1, the momentum component shares cost an average of $1.9 \mathrm{bp} / 1000$ shares, but the value strategy component shares cost an average of $2.16 \mathrm{bp} / 1000$ shares. Looking at the maximum profit-generating operating funds, the value-weighted $\mathrm{BM} / 1 / 3$ strategy generates up to 300 million won in monthly maximum average profit for a size of 70 billion won. This is lower than the profit from the investment in the momentum factor, but the profit of the equal-weighted strategy is shown to be higher than that of momentum. The equal-weighted $\mathrm{BM} / 1 / 6$ strategy is capable of generating up to 1 billion won in monthly maximum average profit from 
205 billion won. This is quite high compared to the fact that the equal-weighted momentum strategy generates maximum profits of between 50 billion won and 200 million won. For more details, refer to Figure 2 which shows the entire profile of the relation between fund size and after-cost return on value factor investing.

Value: EP
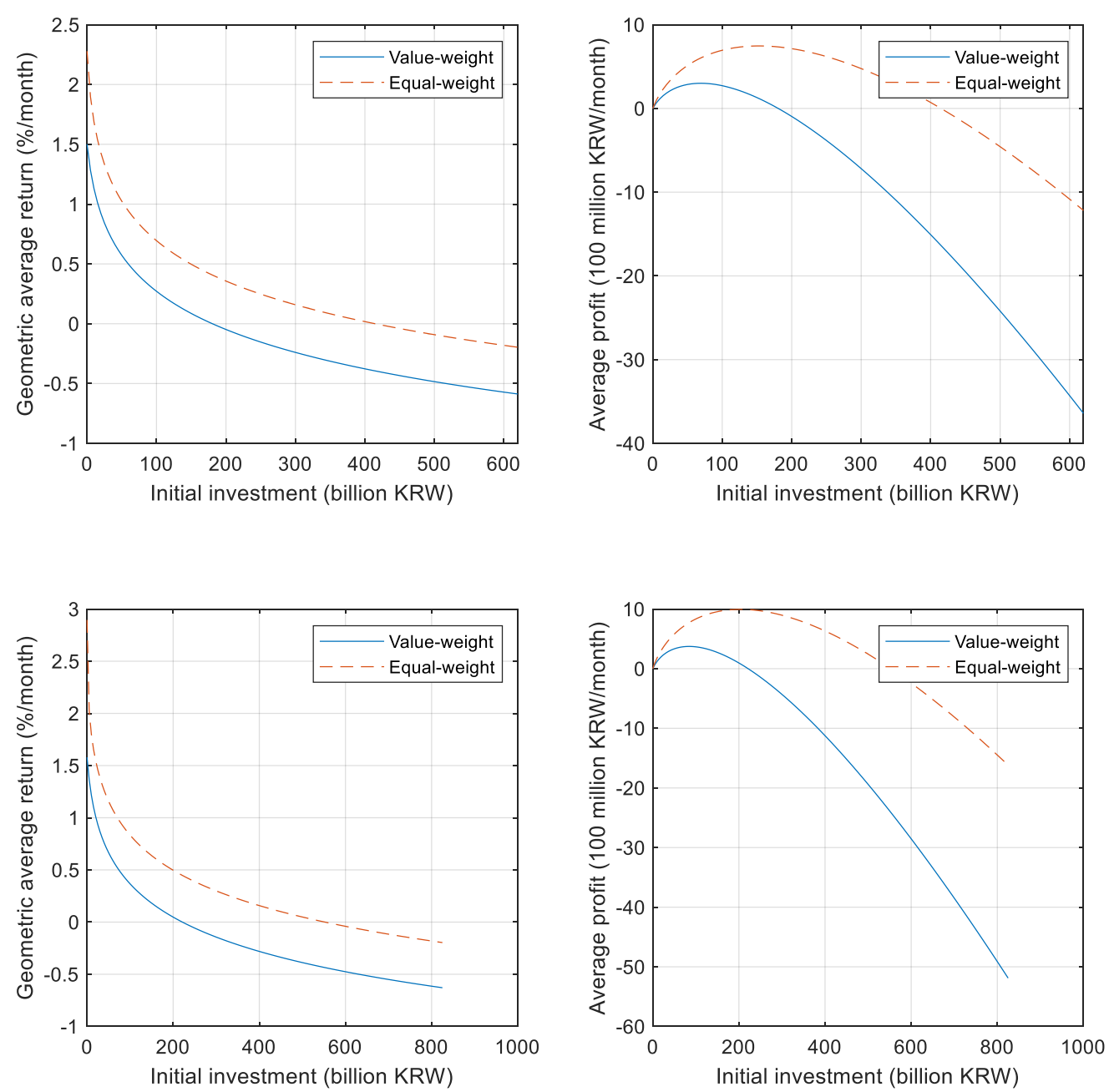

Figure 2. Net-of-cost return on value factor.

Profitability factor strategies use the ratio of total profit to assets (GPA). The average yield is low at 0.55 , but the funding capacity is very high. It was estimated to be able to manage about 1.4 trillion won until the yield reaches $0 \%$. On the other hand, the equal-weighted strategy shows that the average return before the cost reduction is high at $1.3 \%$, but the break-even operating funds was 500 billion won. As shown in Figure 3, the equal-weighted strategy can confirm that the profitability is falling steeply as the price impact is significant and fund size increases. The maximum profit-generating fund size are ranging from 630 to 755 billion won for value-weighted strategies, which is the highest among all factor investments. The monthly average of maximum profits generated from such an operation is between 15 billion won and 1.9 billion won. Even with the equal-weighted strategy, the monthly average of the largest profit can be achieved at 9 to 1.2 billion won when operating at the level of between 200 and 255 billion won, and is the largest profit for all factor investments reviewed in this study. 
Profitability: GP/A
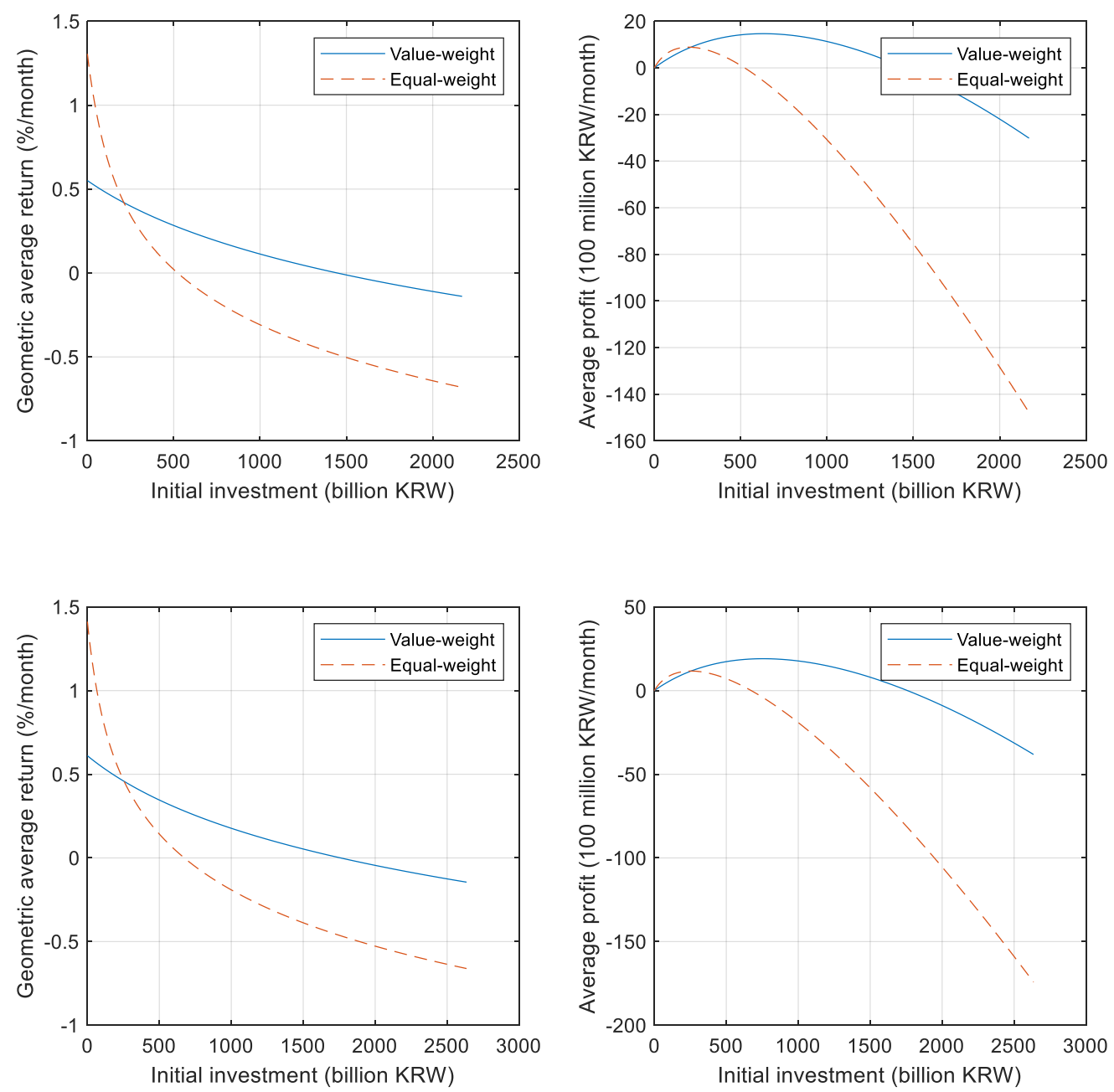

Figure 3. Net-of-cost return on profitability factor.

The market friction factor uses Amihud's illiquidity variable, ILLIQ. A value-weighted portfolio composed of illiquid shares yields an average of $0.84 \%$, but it can be expected that transaction costs due to price shocks will be significantly higher as illiquid shares are included in the factorial definition. The price impact coefficient shown in Table 1 is $2.5 \mathrm{bp} / 1000$ shares on average, which is highest among all strategies. Accordingly, the break-even operating funds will remain at around 80 billion won. As there is a huge impact on price, the longer the holding period and the longer the portfolio adjustment cycle, the greater the effect of reducing transaction costs. As a result, when using $\mathrm{N}=6$ strategy, level of the break-even operating funds will almost double to about 140 billion won. The maximum profit-generating operating fund of the market friction factor is low as about $\$ 35$ million ( 35 billion KRW). The maximum monthly average profit that can be achieved at this time is 100 million won. However, using a value-weighted six-month holding strategy, the company can earn up to 500 million won a month on average for investment worth 100 billion won. For more details, refer to Figure 4 which shows the entire profile of the relation between fund size and after-cost return on friction factor investing. 
Friction: ILLIQ(1)
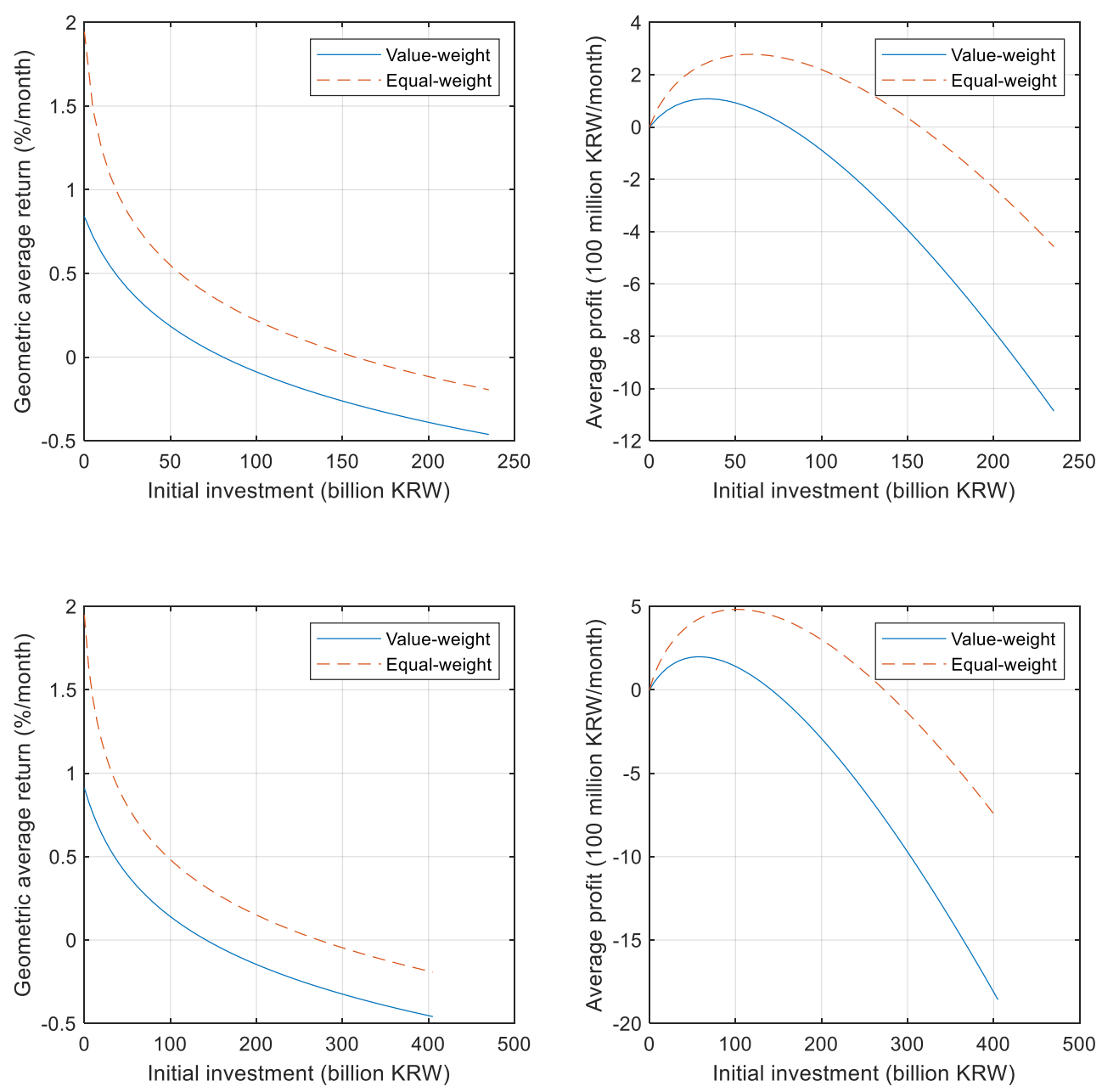

Figure 4. Net-of-cost return on friction factor.

The lottery-like factor uses either a one-month maximum return (MAX (1)) or a one-month return skewness (SKEW1). The lottery-like factor strategy has shown that the capacity on the price impact is lowest, although the pre-cost margin is not low. The MAX (1)/1/3 (or SKEW(1)/1/3) strategy has the lowest break-even operating funds among all factor strategies, with 37.4 billion won (or 26.6 billion won) in value-weighted, and 15 billion won (or 33 billion won) in equal-weighted. The lottery-oriented factor explained by behavioral and financial theory is known as a phenomenon caused by the over-valuation of stocks with strong lottery propensity and the under-valuation of stocks with weak lottery propensity due to the preference of individual investors. Given the fact that $56 \%$ of the KOSPI stock trading volume is generated by individual investors during the analysis period, a lottery-oriented factor, a strategy that invests in stocks not favored by individual investors, has a low level of the capacity of price impacts. Another possibility might be that there is a significant change in the composition or a significant amount of material adjustment of each portfolio adjustment. The relationship between the initial investment amount and the average rate of returns on a factor investment using MAX(1) can be identified through Figure 5. The maximum profit-generating operating funds for lottery-oriented factor investments are 15 billion won on a value-weighted $\operatorname{MAX}(1) / 1 / 3$ strategy basis, which can generate a monthly profit of 0.53 billion won. Finally, the 12-month idiosyncratic volatility (IVOL(12)) and 12-month market beta $\left(\beta_{\mathrm{MKT}}(12)\right)$ are used as low-volatility factors. Although the amount of the break-even operating funds is very low at 38.9 billion KRW when using market beta, the amount of funds for a 3-month holding strategy can be up to 470 billion KRW and amount of strategy for holding for 6 months can be up to 
1.16 trillion KRW when using idiosyncratic volatility. Even with the equal-weighted strategy, profit is generated in the range of 300 to 400 billion KRW. The maximum profit-generating operations are significantly large, with IVOL(12)/1/3 able to achieve an average monthly profit of up to 600 million KRW on a 200 billion KRW scale, and IVOL(12)/1/6 achieving a profit of 1.5 billion KRW on a 485 billion KRW scale. As shown in Figure 6, the value-weighted IVOL(12)/1/6 strategy (Panel B) shows that the return curve decreases very smoothly, with a low level of pre-cost return but no significant impact of price shocks on the scale of operation. As a result, the break-even fund size is large. However, the defensive factor strategy using market beta does not seem to have much capacity in the Korean stock market. The reason for this is not attributed to price impact costs. Seeing the average return before cost, the reason is that the beta anomaly is not very significant in Korea.

Lottery-like: $\operatorname{MAX}(1)$
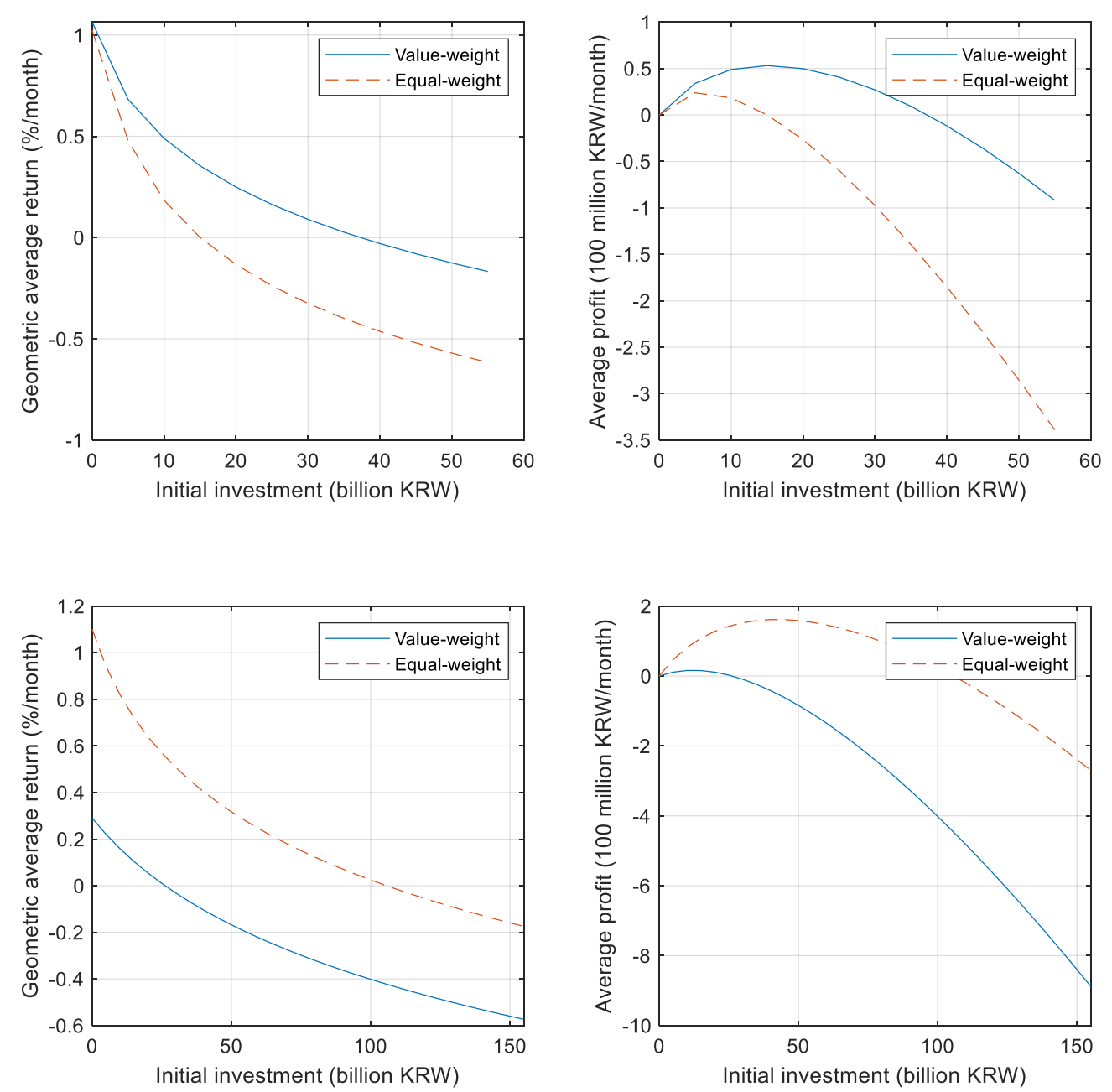

Figure 5. Net-of-cost return on lottery-like factor. 
Defensive: IVOL(12)
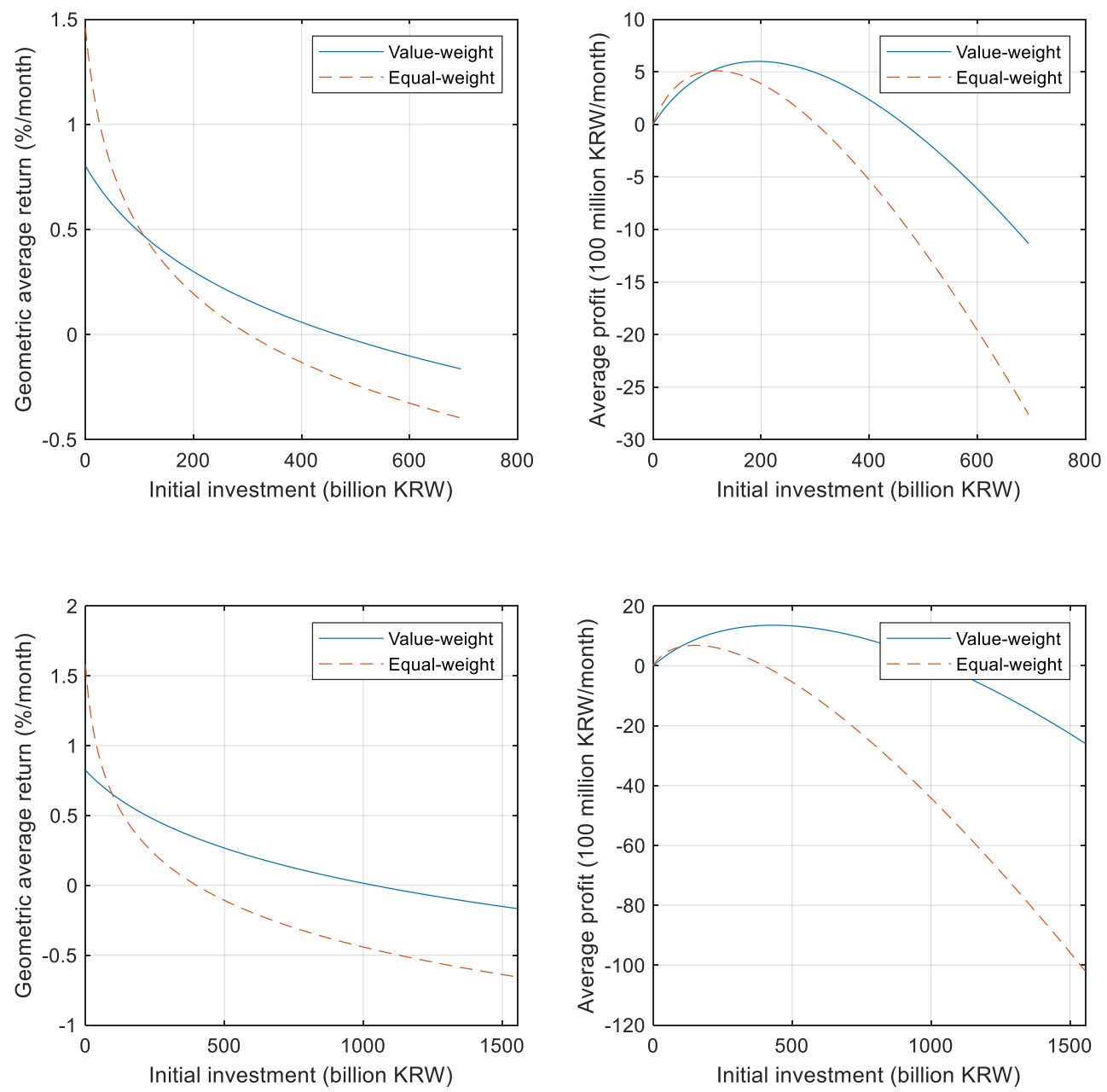

Figure 6. Net-of-cost return on defensive factor.

\section{Discussion}

It is worth noting that the amount of operating funds in the break-even point and of fund size generating maximum profit in this study were estimated as of the end of December 2000. Considering that the market capitalization of the KOSPI has more than quadrupled since the end of 2017, and that the volume of the transaction has nearly tripled, the factor investment that starts operating now will be able to operate on a much larger scale than the results of this study. For example, the most commonly used momentum or value factor is estimated to generate the largest profit in the range of 70 billion to 100 billion won, which, in proportion to the market size, would enable operations of 300 to 400 billion won.

The investment strategy with the highest pre-cost return is BM/1/6, PRET(10,0)/1/3 in value weighting, PRET $(10,0) / 1 / 6$, and BM/1/6 strategy in equal weighing, which shows that investment in value factors or momentum factors is primarily profitable. This is consistent with the results revealed in previous research.

Considering the transaction costs caused by price shocks, the factor with the highest investment capacity is the profitability factor. Specifically, the value-weighted GPA/1/6 operating profit and loss amount was 1.7 trillion won, while the same weighting GPA/1/6 was the highest with 670 billion won. Excluding the profitability factor, the amount of operating capital in the break-even point is also quite high, as the investment in momentum or value factor is profitable before the cost was deducted. 
The value-weighted IVOL(12)/1/6 strategy also showed a very high level of break-even point at around 1 trillion won, but it was difficult to generalize as a whole the low-varying factor.

Maximum profits that can be generated in a non-linear relationship between operating size and cost reduction is generated from a profitability factor. Value-weighted GPA/1/6 is able to achieve an average monthly profit of 1.9 billion won, and the same weighted strategy is able to generate an average profit of 1.2 billion won. The strategy of idiosyncratic volatility factor among low-varying factors can be achieved by up to 1.5 billion won, so the idiosyncratic volatility factor strategy is also an attractive factor when considering costs.

\section{Conclusions}

Using the KS methodology under the assumption of the cost function of BHK, this study analyzed the effect of price impact costs on the profitability of factor investments. Specifically, we investigated the pre-cost return that is a return when simulating an investment strategy with historical data, and examined further how the return on investment varies with the size of fund operations. With this method, we estimated the amount of funds in the break-even point and the amount of investment that would generate the maximum profits. Our finding suggests that factor investing is implementable for the profitability, defensive, and momentum factors even if the transaction is massive. Our research has limitations in that we did not directly estimate the cost function of Korea because of data availability. Instead, we borrowed the estimated parameters of the U.S. market with the assumption that there is no structural difference. We leave a direct estimation of cost function as future research.

Author Contributions: The authors contributed to this paper as follows. J.K.: software, formal analysis, investigation, data curation, writing-original draft preparation; Y.J.P.: methodology, validation, writing-review and editing, supervision, project administration.

Funding: This research was supported by Hallym University Research Fund, HRF-201907-008.

Conflicts of Interest: The authors declare no conflict of interest.

\section{References}

1. Clarke, R.; de Silva, H.; Thorley, S. Fundamentals of Efficient Factor Investing (corrected May 2017). Financ. Anal. J. 2016, 72, 9-26. [CrossRef]

2. Dimson, E.; Marsh, P.; Staunton, M. Factor-Based Investing: The Long-Term Evidence. J. Portf. Manag. 2017, 43, 15-37. [CrossRef]

3. van Gelderen, E.; Huij, J. Academic Knowledge Dissemination in the Mutual Fund Industry: Can Mutual Funds Successfully Adopt Factor Investing Strategies? J. Portf. Manag. 2014, 40, 157-167. [CrossRef]

4. Houweling, P.; van Zundert, J. Factor Investing in the Corporate Bond Market. Financ. Anal. J. 2017, 73, 100-115. [CrossRef]

5. Kim, J.H.; Kim, W.C.; Fabozzi, F.J. Robust Factor-Based Investing. J. Portf. Manag. 2017, 43, 157-164. [CrossRef]

6. Asness, C.; Frazzini, A.; Israel, R.; Moskowitz, T. Fact, Fiction, and Momentum Investing. J. Portf. Manag. 2014, 40, 75-92. [CrossRef]

7. Harvey, C.R.; Liu, Y.; Zhu, H. ... and the Cross-Section of Expected Returns. Rev. Financ. Stud. 2016, 29, 5-68. [CrossRef]

8. Hou, K.; Xue, C.; Zhang, L. Replicating Anomalies. Rev. Financ. Stud. 2018. [CrossRef]

9. Linnainmaa, J.T.; Roberts, M.R. The History of the Cross-Section of Stock Returns. Rev. Financ. Stud. 2018, 31, 2606-2649. [CrossRef]

10. Parmler, J.; González, A. Is Momentum Due to Data-snooping? Eur. J. Financ. 2007, 13, 301-318. [CrossRef]

11. Engelberg, J.; Mclean, R.D.; Pontiff, J. Anomalies and News. J. Financ. 2018, 73, 1971-2001. [CrossRef]

12. Scharfstein, D.S.; Stein, J.C. Herd Behavior and Investment. Am. Econ. Rev. 1990, 80, 465-479.

13. Banerjee, A.V. A Simple Model of Herd Behavior. Q. J. Econ. 1992, 107, 797-817. [CrossRef]

14. Marquering, W.; Nisser, J.; Valla, T. Disappearing anomalies: A dynamic analysis of the persistence of anomalies. Appl. Financ. Econ. 2006, 16, 291-302. [CrossRef] 
15. Krkoska, E.; Schenk-Hoppé, K.R. Herding in Smart-Beta Investment Products. J. Risk Financ. Manag. 2019, 12, 47. [CrossRef]

16. Chui, A.C.W.; Wei, K.C.J. Book-to-market, firm size, and the turn-of-the-year effect: Evidence from Pacific-Basin emerging markets. Pac.-Basin Financ. J. 1998, 6, 275-293. [CrossRef]

17. Hameed, A.; Kusnadi, Y. Momentum Strategies: Evidence from Pacific Basin Stock Markets. J. Financ. Res. 2002, 25, 383-397. [CrossRef]

18. Cakici, N.; Fabozzi, F.J.; Tan, S. Size, value, and momentum in emerging market stock returns. Emerg. Mark. Rev. 2013, 16, 46-65. [CrossRef]

19. Nartea, G.V.; Wu, J.; Liu, H.T. Extreme returns in emerging stock markets: evidence of a MAX effect in South Korea. Appl. Financ. Econ. 2014, 24, 425-435. [CrossRef]

20. Hung, C.-H.D.; Banerjee, A.N. How do momentum strategies 'score' against individual investors in Taiwan, Hong Kong and Korea? Emerg. Mark. Rev. 2014, 21, 67-81. [CrossRef]

21. Jegadeesh, N.; Titman, S. Returns to buying winners and selling losers: Implications for stock market efficiency. J. Financ. 1993, 48, 65-91. [CrossRef]

22. Domowitz, I.; Glen, J.; Madhavan, A. Liquidity, Volatility and Equity Trading Costs Across Countries and Over Time. Int. Financ. 2001, 4, 221-255. [CrossRef]

23. O'Neill, M.J.; Warren, G.J. Evaluating fund capacity: Issues and methods. Account. Financ. 2019, 59, 773-800. [CrossRef]

24. Korajczyk, R.A.; Sadka, R. Are momentum profits robust to trading costs? J. Financ. 2004, 59, $1039-1082$. [CrossRef]

25. Chen, Z.; Stanzl, W.; Watanabe, M. Price Impact Costs and the Limit of Arbitrage. Yale School of Management Working Paper Ysm251 2002. Yale School of Management, revised 08 Jun 2006. Available online: https: //ideas.repec.org/p/ysm/somwrk/ysm251.html (accessed on 29 July 2019).

26. Frazzini, A.; Israel, R.; Moskowitz, T.J. Trading Costs of Asset Pricing Anomalies. Fama-Miller Working Paper. Available online: https://ssrn.com/abstract=2294498orhttp://dx.doi.org/10.2139/ssrn.2294498 (accessed on 29 July 2019).

27. Novy-Marx, R.; Velikov, M. A Taxonomy of Anomalies and Their Trading Costs. Rev. Financ. Stud. 2016, 29, 104-147. [CrossRef]

28. Li, F.; Chow, T.-M.; Pickard, A.; Garg, Y. Transaction Costs of Factor-Investing Strategies. Financ. Anal. J. 2019, 75, 62-78. [CrossRef]

29. Ratcliffe, R.; Miranda, P.; Ang, A. Capacity of Smart Beta Strategies from a Transaction Cost Perspective. J. Index Invest. 2017, 8, 39-50. [CrossRef]

30. Blitz, D.; Marchesini, T. The Capacity of Factor Strategies. J. Portf. Manag. 2019. [CrossRef]

31. Bertsimas, D.; Lo, A.W. Optimal control of execution costs. J. Financ. Mark. 1998, 1, 1-50. [CrossRef]

32. Breen, W.J.; Hodrick, L.S.; Korajczyk, R.A. Predicting Equity Liquidity. Manag. Sci. 2002, 48, 470-483. [CrossRef]

33. Kyle, A.S. Continuous Auctions and Insider Trading. Econometrica 1985, 53, 1315-1335. [CrossRef]

34. Hasbrouck, J. Trades, quotes, inventories, and information. J. Financ. Econ. 1988, 22, 229-252. [CrossRef]

35. Hasbrouck, J. Measuring the information content of stock trades. J. Financ. 1991, 46, 179-207. [CrossRef]

36. Hasbrouck, J. Trading Costs and Returns for U.S. Equities: Estimating Effective Costs from Daily Data. J. Financ. 2009, 64, 1445-1477. [CrossRef]

37. Cont, R.; Kukanov, A.; Stoikov, S. The Price Impact of Order Book Events. J. Financ. Econ. 2014, $21,47-88$. [CrossRef]

38. Fama, E.F.; French, K.R. Multifactor Explanations of Asset Pricing Anomalies. J. Financ. 1996, 51, 55-84. [CrossRef]

39. Fama, E.F.; French, K.R. A five-factor asset pricing model. J. Financ. Econ. 2015, 116, 1-22. [CrossRef]

40. Jones, C.M.; Lamont, O.A. Short-sale constraints and stock returns. J. Financ. Econ. 2002, 66, $207-239$. [CrossRef]

41. Nagel, S. Short sales, institutional investors and the cross-section of stock returns. J. Financ. Econ. 2005, 78, 277-309. [CrossRef]

42. Beber, A.; Pagano, M. Short-Selling Bans Around the World: Evidence from the 2007-09 Crisis. J. Financ. 2013, 68, 343-381. [CrossRef] 
43. Basu, S. The relationship between earnings' yield, market value and return for NYSE common stocks: Further evidence. J. Financ. Econ. 1983, 12, 129-156. [CrossRef]

44. Novy-Marx, R. The other side of value: The gross profitability premium. J. Financ. Econ. 2013, 108, 1-28. [CrossRef]

45. Amihud, Y. Illiquidity and stock returns: cross-section and time-series effects. J. Financ. Mark. 2002, 5, 31-56. [CrossRef]

46. Bali, T.G.; Cakici, N.; Whitelaw, R.F. Maxing out: Stocks as lotteries and the cross-section of expected returns. J. Financ. Econ. 2011, 99, 427-446. [CrossRef]

47. Ang, A.; Hodrick, R.J.; Xing, Y.; Zhang, X. The Cross-Section of Volatility and Expected Returns. J. Financ. 2006, 61, 259-299. [CrossRef]

(C) 2019 by the authors. Licensee MDPI, Basel, Switzerland. This article is an open access article distributed under the terms and conditions of the Creative Commons Attribution (CC BY) license (http://creativecommons.org/licenses/by/4.0/). 